\section{Macrolide antibiotics and cystic fibrosis}

\section{G Peckham}

\section{Do the macrolides have a role in the treatment of cystic fibrosis?}

7 here is growing interest in the potential use of macrolide antibiotics as anti-inflammatory agents in cystic fibrosis. This stems from the dramatic success of long term erythromycin in the treatment of diffuse panbronchiolitis (DPB), a condition with a high prevalence in Japan but rare elsewhere. ${ }^{1-3}$ Clinically, DPB exhibits some similarities to cystic fibrosis including chronic productive cough, exertional dyspnoea, chronic sinusitis, mucoid Pseudomonas aeruginosa colonisation, and bronchiectasis. The introduction of erythromycin as a treatment for DPB has had a dramatic impact on mortality, increasing 10 year survival from 12.4 $21.9 \%$ to over $90 \%$ in those colonised with $P$ aeruginosa. ${ }^{3}{ }^{4}$ Similar success has been reported with clarithromycin, roxithromycin, and azithromycin. ${ }^{13}$ While the aetiology of both conditions may be very different, it is the similarities which beg the question "do the macrolides have a role in the treatment of cystic fibrosis?"

The macrolide antibiotics are an in triguing group of drugs with both anti-inflammatory and antibacterial properties. ${ }^{4}$ Their mode of action in DPB is thought to be mediated by mechanisms other than antibacterial as the effect occurs below the minimum inhibitory concentration required for bacteria such as Haemophilus influenzae and $P$ aeruginosa. $^{13}$

There are several theoretical reasons why the macrolides could modulate the disease process in cystic fibrosis. Firstly, airway inflammation, as in DPB, is recognised as a major factor in the pathogenesis of cystic fibrosis lung disease. ${ }^{5-7}$ Anti-inflammatory drugs such as high doses of non-steroidal antiinflammatory agents and prednisolone have been shown to slow the decline of lung function in patients with cystic fibrosis. ${ }^{8-10}$ Several studies suggest that the macrolides also possess important anti-inflammatory activity which appears to be mediated by an inhibition of neutrophil chemotaxis, reduction of neutrophil elastase, and modification of pro-inflammatory cytokines with suppression of interleukin (IL)-1 $\beta$, IL-6, IL-8, and tumour necrosis factor
(TNF)- $\alpha$ production. ${ }^{12} 411$ Secondly, they reduce sputum viscoelasticity and airway adhesion of $P$ aeruginosa. ${ }^{212}{ }^{13}$ Certain macrolides have the innate ability to increase the killing of mucoid $P$ aeruginosa, a mechanism that may be mediated by their ability to disrupt the integrity of the protective biofilm and impair the transformation of non-mucoid $P$ aeruginosa to the more virulent mucoid phenotype. ${ }^{14-16}$

The clinical evidence to support the use of macrolides in the treatment of cystic fibrosis is poor. Most of the studies have only been published in abstract form and are usually anecdotal with small numbers of patients. Frederiksen et al reported a larger randomised, double blind, placebo controlled, crossover study of the effect of twice daily clarithromycin in cystic fibrosis. ${ }^{17}$ Various parameters were measured including pulmonary function but, unexpectedly, 20 of 41 patients were excluded from the study so that no conclusions could be drawn. Importantly, failure to complete the study was not related to the active arm.

\section{"Treatment with azithromycin was associated with significantly fewer courses of intravenous antibiotics, maintenance of lung function, reduction in median CRP levels, and improvement in quality of life scores"}

In this issue of Thorax Wolter et al report their findings of the first published prospective, randomised, placebo controlled trial investigating the clinical effect of macrolides in the treatment of cystic fibrosis. ${ }^{18}$ A total of 49 adults with cystic fibrosis completed the 3 month trial of $250 \mathrm{mg}$ azithromycin versus placebo. Treatment with azithromycin was associated with significantly fewer courses of intravenous antibiotics, maintenance of lung function, reduction in median $\mathrm{C}$ reactive protein (CRP) levels, and improvement in quality of life scores. While there was no difference in baseline microbiology, Staphylococcus aureus was isolated from $41.3 \%$ of patients at the start of the study. This suggests that some of the clinical response seen in the azithromycin group may have been mediated through the antibacterial activity of the drug. Similar results have been reported in children. In a nonrandomised open labelled study Pirzada et al compared the effect of $250 \mathrm{mg}$ azithromycin in 18 children with cystic fibrosis and 18 age and sex matched controls over a mean of 0.78 years. ${ }^{18}$ The azithromycin treated group showed significant improvement in lung function and weight gain. The drug was well tolerated and no significant side effects were observed.

In the only other study to be formally published, Jaffe et al reported their findings from an open study of seven children with cystic fibrosis given $250 \mathrm{mg}$ azithromycin for more than 3 months. ${ }^{20}$ Although azithromycin was associated with a significant increase in lung function, the results are difficult to interpret.

While the study by Wolter et al supports the potential role of macrolides in the treatment of cystic fibrosis, larger double blind, placebo controlled trials are needed which can differentiate between the anti-inflammatory and antibacterial properties of these agents. With the potential ability of the macrolides to alter the complex bacteria/epithelial/ biofilm interaction, it is possible that they may have a role both in reducing the incidence of new $P$ aeruginosa colonisation and improving conventional early eradication treatment. ${ }^{21}$

Thorax 2002;57: 189-190

\section{Author's affiliation}

D G Peckham, Regional Adult CF Unit, Seacroft Hospital, Leeds LS1 4 6UH, UK

Correspondence to: Dr D Peckham, Regional Adult CF Unit, Seacroft Hospital, Leeds LSI 4 6UH, UK

\section{REFERENCES}

1 Koyama H, Geddes DM. Erythromycin and diffuse panbronchiolitis. Thorax 1997:52:915-8.

2 Jaffe A, Bush A. Anti-inflammatory effects of macrolides in lung disease. Pediatr Pulmonol 2001;31:464-73.

3 Hoiby H. Diffuse panbronchiolitis and cystic fibrosis: East meets West. Thorax 1994:49:531-2.

4 Black PN. Anti-inflammatory effects of macrolide antibiotics. Eur Respir $J$ 1997; 10:971-2

5 Armstrong DS, Grimwood K, Carzino R, et al. Lower respiratory tract infection and inflammation in infants with newly diagnosed cystic fibrosis. BM 1995;310:1571-2.

6 Kahn TZ, Wagener JS, Bost T, et al. Early pulmonary inflammation in infants with cystic fibrosis. Am J Respir Crit Care Med 1995; 151:1075-82. 


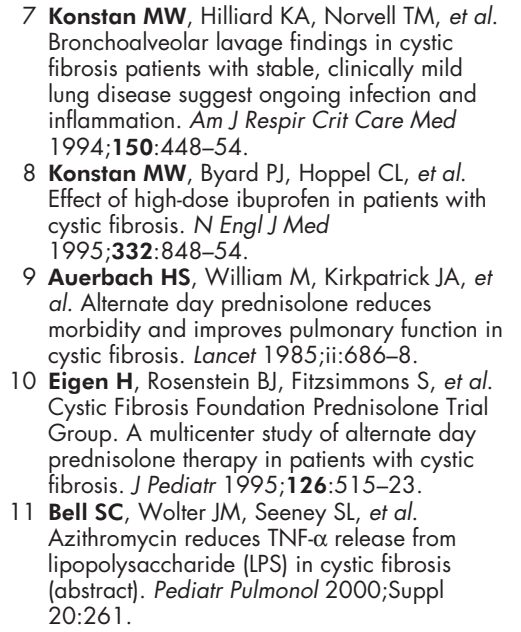

12 Tai S, Sudo E, Sun F, et al. Effect of azithromycin on sputum rheology in cystic fibrosis patients (abstract). Pediatr Pulmonol 1999:Suppl 19:264.

13 Fisher JJ, Baumon U, Gudowius P, et al. Azithromycin reduces epithelial adherence of $P$ aeruginosa in patients with cystic fibrosis (abstract). Pediatr Pulmonol 1999;Suppl 19:265.

14 Yasuda H, Ajiki Y, Koga, T, et al. Interaction between biofilms formed by Pseudomonas aeruginosa and clarithromycin. Antimicrob Agents Chemother 1993;37:1749-55.

15 Kobayashi H. Biofilm disease: its clinical manifestation and therapeutic possibilities of macrolides. Am J Med 1995;99:26-30.

16 Kobayashi O, Moser C, Jensen PO, et al. Azithromycin treatment inhibits induction of mucoid phenotype in susceptible BALB/c mice with chronic Pseudomonas aeruginosa lung infection (abstract). In: Proceedings of XIIIth International Cystic Fibrosis Congress, Stockholm, Sweden 2000: 164.
17 Frederiksen B, Koch C, Hoiby N, et al. Clinical efficacy of clarithromycin in CF patients with chronic lung infection. Abstracts of the 24th European Cystic Fibrosis Conference, Vienna, Austria 2001:P208

18 Wolter J, Seeney S, Bell S. Effect of long term treatment with azithromycin on disease parameters in cystic fibrosis: a randomised trial. Thorax 2002;57:212-6.

19 Pirzada OM, Taylor CJ. Long-term macrolide antibiotics improve pulmonary function in cystic fibrosis (abstract). Pediatr Pulmonol 1999; Suppl 19:263

20 Jaffe A, Jackie F, Rosenthal $M$, et al. Long-term azithromycin may improve lung function in children with cystic fibrosis. Lancet 1998;351:420.

21 Frederiksen B, Koch C, Hoiby N. Antibiotic treatment at time of initial colonisation with Pseudomonas aeruginosa postpones chronic infection and prevents deterioration in pulmonary function in patients with cystic fibrosis. Pediatr Pulmonol 1997;23:330-5.

\section{Psychological factors in asthma control and attack risk}

\section{M Osman}

\section{The risk of asthma episodes may depend on a complex relationship between psychological factors and the experience of a recent attack.}

$\mathrm{n}$ a series of Australian studies Yellowlees, ${ }^{1}$ Ruffin, ${ }^{2}$ and Campbell ${ }^{3}$ have found high rates of anxiety and panic disorder among patients who have suffered near fatal asthma episodes. In the UK Ayres and coworkers have found a high lifetime prevalence of psychiatric symptoms and psychiatric morbidity in patients with brittle asthma. ${ }^{45}$ Both the Australian studies and that by Ayres et al report a consistent pattern of high levels of denial of asthma and delay in seeking help in acute attacks. The confidential enquiries into asthma deaths ${ }^{6-8}$ suggest that psychological factors including denial and delay contribute to some deaths. Patients who had died from asthma were more likely to be those who found it difficult to cooperate with medical management.

However, these studies only refer to a small minority of asthma patients, are post hoc, and may be relevant only to a special group of asthmatic subjects. It is not easy to translate these findings for very severe high risk subjects to moderate asthmatics in general practice.

Anxiety is not always found to be higher among patients with poorly controlled asthma. Barboni et al $l^{9}$ compared patients with near fatal asthma with a group of matched controls and found no difference in psychiatric anxiety scores between the two groups. Boseley et $a l^{10}$ found no significant difference in anxiety between adherent and non-adherent patients. Some anxiety may be useful in self-management. Spinhoven et al found that anxious subjects were more accurate in detecting a fault in forced expiratory volume in 1 second $\left(\mathrm{FEV}_{1}\right)$ on bronchial challenge than non-anxious subjects; they hypothesised that anxiety might produce greater vigilance. On the other hand, greater accuracy of perception of variability in asthma might lead to greater anxiety.

Delay and denial have frequently been identified in qualitative studies of the attitudes of asthma patients to selfmanagement. In one study ${ }^{12}$ in which 30 general practice patients with a diagnosis of asthma prescribed regular inhaled steroids were interviewed, about half the patients accepted their asthma and used regular daily inhaled steroids or had a pragmatic approach to asthma control using inhaled steroids intermittently but reporting that this strategy was successful. The other $50 \%$ of interviewees did not accept that they had asthma and were classified as "deniers". Their selfdefinition commonly was that they had a "bad chest" which resulted in intermittent illness but was not a permanent condition. None of the "deniers" used their prescribed inhaled steroid. Denial was related to seeing asthma as a stigmatised illness and also to seeing themselves as people who could "cope". To these subjects, acceptance of a selfdefinition of having asthma and using a preventer regularly would mean that they were "not coping".

Janson and Becker ${ }^{13}$ prospectively followed 95 patients with asthma and assessed the reasons for the type of action taken when acute episodes occurred. They found that a delay in seeking help was common due to attitudes ranging from fear of steroids to the need to "tough it out"; however, they also found that a small but significant minority identified a pivotal episode in their dealing with acute asthma which changed their attitude to selfmanagement.

The post hoc studies described at the beginning of this article present us with a believable association between denial, psychological morbidity, and a high risk of adverse outcome but they have the limitation of working backwards from a non-representative group. The qualitative studies support the belief that denial and delay are linked to patient willingness to cooperate actively in asthma selfmanagement, but leave unanswered the question of the objective risk of acute episodes associated with different psychological patterns and attitudes to management. Among patients with moderate asthma, are "deniers" more at risk of acute episodes than patients who accept their asthma? In Janson's study was there any evidence that the patients who described themselves as having a pivotal experience that changed their attitudes to their asthma actually did demonstrate more successful asthma control?

Few studies have looked at the prospective consequences of psychological attitudes. In the 1980s Kaptein ${ }^{14}$ showed 
that patients admitted with asthma who had high anxiety scores were more likely to be re-admitted within 6 months. One recent study by Adams et $a l^{15}$ in hospital outpatients has shown that the prospective risk of admission was related to greater use of strategies such as "hoping for a miracle" to cure asthma.

In this issue of Thorax the paper by Greaves et $\mathrm{l}^{16}$ complements the findings by Adams et al and presents new data on how the effect of psychological factors on the risk of asthma episodes may depend on a complex relationship between psychological factors and the experience of a recent attack. We might expect patients who have had recent attacks to have low confidence, a high fear of attack, and a high risk of future attacks. Conversely, we would expect patients who have successfully controlled asthma for more than a year to have low anxiety/fear, high confidence, and a low risk of future attacks. Greaves et al show that the story is not so simple. Past attack experience does not completely explain patient differences in panic fear and confidence, and high confidence in a patient has different implications for the risk of an acute attack depending on whether the patient has a history of well controlled or poorly controlled asthma. They conclude that fear of attack is undesirable in patients with good asthma control but is good in patients with poor control. Similarly, confidence in control is good if asthma is well controlled, but too much confidence is bad if asthma is poorly controlled. Dirks et $a l^{17}$ found more than 20 years ago that hospitalisation was more common in both patients with very high and very low levels of anxiety. The persistence of this pattern is striking as medical management of asthma has changed dramatically since the 1980s.

\section{"Recent attack experience is an important mediator of patient behaviour and attitudes to asthma management"}

The study by Greaves et $a l^{16}$ suggests that there may "good" and "bad" denial of asthma symptoms. It is good for patients with well controlled asthma to be confident in their control and not to be fearful about their asthma, and this may be a form of "positive denial". Equally, lack of confidence in patients with stable asthma is not a good sign. Lack of confidence may be associated with depression and poor quality of life. In our own study in general practice patients with mild to moderate asthma ${ }^{18}$ we found that poor quality of life was a prospective predictor of GP contact for asthma independent of asthma symptoms. Conversely, patients with high asthma confidence scores but who have poorly controlled asthma are expressing a belief in their ability to control episodes which is not warranted by their attack history. This is a denial of the need to change their self-management. This overconfidence is likely to be associated with poor compliance and delay in taking action during episodes. Chambers et $a l^{19}$ found that the most frequent reason patients gave for non-use or intermittent use of inhaled corticosteroids was a belief that inhaled steroids were unnecessary during nonsymptomatic periods. Factors associated with regular use of inhaled steroids were belief about the value of active participation with their doctor in self-care and belief that asthma was a serious health problem.

It would be of value to carry out further studies to determine whether the high confidence/high risk group in the study by Greaves et al is less compliant than the other groups described in the study .

Greaves et al suggest that the period immediately after a serious asthma episode may be a particularly important time for educating and negotiating with patients to change their selfmanagement attitudes and behaviour. This is likely to be of critical importance for overconfident asthma patients who may comprise a significant minority of patients in general practice.

In conclusion, the study by Greaves et al makes clear that recent attack experience is an important mediator of patient behaviour and attitudes to asthma management. Future studies should be mindful of this.

Thorax 2002;57:190-191

Author's affiliation

L M Osman, Chest Clinic, Aberdeen Royal Infirmary, Aberdeen AB25 2ZN, UK

Correspondence to: $\operatorname{Dr} L$ M Osman, Chest

Clinic, Aberdeen Royal Infirmary, Aberdeen AB25 2ZN, UK; I.osman@abdn.ac.uk

\section{REFERENCES}

1 Yellowlees PM, Ruffin RE. Psychological defences and coping styles in patients following a life-threatening attack of asthma. Chest 1989:95:1298-303.

2 Ruffin RE, Latimer KM, Schembri DA Longitudinal study of near fatal asthma. Chest 1991;99:77-83.

3 Campbell DA, Yellowlees PM, McLennan G, et al. Psychiatric and medical features of near fatal asthma. Thorax 1995;50:254-9.

4 Miles JF, Garden GM, Tunnicliffe WS, et al. Psychological morbidity and coping skills in patients with brittle and non-brittle asthma: a case-control study. Clin Exp Allergy 1997;27:1151-9.

5 Garden GM, Ayres JG. Psychiatric and social aspects of brittle asthma. Thorax 1993;48:501-5

6 Mohan G, Harrison BD, Badminton RM, et al. A confidential enquiry into deaths caused by asthma in an English health region: implications for general practice. Br J Gen Pract 1996;46:529-32

7 Burr ML, Davies BH, Hoare A, et al. A confidential inquiry into asthma deaths in Wales. Thorax 1999:54:985-9.

8 Bucknall CE, Slack R, Godley CC, et al Scottish Confidential Inquiry into Asthma Deaths (SCIAD), 1994-6. Thorax 1999;54:978-84.

9 Barboni E, Peratoner A, Rocco PL, et al. Near fatal asthma and psychopathological characteristics: a group-control study. Monald Arch Chest Dis 1997;52:339-42.

10 Bosley CM, Fosbury JA, Cochrane GM. The psychological factors associated with poor compliance with treatment in asthma. Eur Respir J 1995;8:899-904.

11 Spinhoven P, Peski-Oosterbaan AS, Van der Does $\mathrm{A}$, et al. Association of anxiety with perception of histamine induced bronchoconstriction in patients with asthma Thorax 1997;52: 149-52.

12 Adams S, Pill R, Jones A. Medication, chronic illness and identity: the perspective of people with asthma. Soc Sci Med 1997;45:189201

13 Janson S, Becker G. Reasons for delay in seeking treatment for acute asthma: the patient's perspective. J Asthma 1998;35:427-35.

14 Kaptein AA. Psychological correlates of length of hospitalization and rehospitalization in patients with acute, severe asthma. Soc Sci Med 1982;16:725-9.

15 Adams RJ, Smith BJ, Ruffin RE. Factors associated with hospital admissions and repeat emergency department visits for adults with asthma. Thorax 2000;55:566-73.

16 Greaves CJ, Eiser C, Seamark D, et al. Attack context: an important mediator of the relationship between psychological status and asthma outcomes. Thorax 2002;57:217-21.

17 Dirks JF, Kinsman RA, Horton DJ, et al. Panic-fear in asthma: rehospitalization following intensive long-term treatment. Psychosom Med 1978:40:5-13.

18 Osman LM, Calder C, Robertson R, et al Symptoms, quality of life, and health service contact among young adults with mild asthma. Am J Respir Crit Care Med 2000:161:498-503

19 Chambers CV, Markson L, Diamond JJ, et al Health beliefs and compliance with inhaled corticosteroids by asthmatic patients in primary care practices. Respir Med 1999;93:88-94. 